\title{
Sports Specific Influence on Force Vital Capacity in University Players
}

\author{
Dr. Arvind Malik ${ }^{1}$, Dr. Sonia Malik², Satender Kumar ${ }^{3}$, \\ ${ }^{1}$ Professor, Department of Physical Education, Kurukshetra University, Kurukshetra, Haryana. \\ ${ }^{2}$ Associate Professor, Arya Girls College Shahadad (M), Haryana \\ ${ }^{3}$ Research Scholar, Department of Physical Education, Kurukshetra University, Kurukshetra, Haryana.
}

\begin{abstract}
:
Objective: The objective of this research was to study the pulmonary function in different types of sports and compare them with controls in order to find out which sports improve lung function the most.

Methods: This was a cross-sectional study involving 240 sportsmen of eight different games (30 of each): Basketball, Volleyball, Athletics (long \& short distance Runners), Boxing (Fly to Middle weight boxers), Wrestling (57 to $86 \mathrm{~kg}$ ), Swimming and Control group (Non-sportsmen).The Force Vital Capacity (FVC) was measured with Minispir ${ }^{\circledR}$ New, Computer-based Spirometer.

Results: The $t$-value of Force Vital Capacity $(F V C)(L / S)$ for Non-Sports $(M-3.96 \pm 0.39) v / s$ Swimming (M $4.68 \pm 0.55)$ was $5.65(p<0.001)$ and that of Non-Sports $(M-3.96 \pm 0.39)$ and Volley Ball $(5.32 \pm 0.43)$ was 12.91(p<0.001). Similarly, the boxers, wrestlers and swimmers were found with significant better FVC in comparison to control group.

Conclusions: Our results suggest that the different sport activities performed $\geq 16 \mathrm{~h}$ per week have a significant impact on the physiological adaptation of the respiratory system.
\end{abstract}

Keywords: Force Vital Capacity; Athletes; Sports; Respiratory function tests.

\section{Introduction}

According to World Health Statistics 2016 report, the 17 Sustainable Development Goals (SDGs) of the 2030, Health is centrally positioned, with one comprehensive goal (SDG 3) and its 13 targets covering all major health priorities, and links to targets in many of the other goals. WHO has predicted lifestyle-related chronic diseases - mainly cardiovascular disease, diabetes, cancer and chronic respiratory disease - will account for two thirds of all the deaths globally in next 25 years. Economic accountability as per WHO (2016) estimate between 2005 and 2015 will increase to around US - 558 (\$) billion in China, 237(\$) billion in India, 303(\$) billion in Russia and 33 (\$) billion in the U.K.

Physical inactivity is now identified as the fourth leading risk factor for global mortality. Physical inactivity, along with a sedentary lifestyle, is now a global 'non-communicable' disease. WHO (2010) Global Recommendations on Physical Activity for Health suggests that Adults aged 18-64 should do at least 150 minutes of moderate-intensity aerobic physical activity throughout the week. Physical activity is positively related to cardiorespiratory fitness in children and youth, and both preadolescents and adolescents can achieve improvements in cardiorespiratory fitness with exercise training Losnegard T et al. (2014) .

Pulmonary function tests (PFT) serve as a tool of health evaluation and also to some extent as a predictor of survival rate. PFT tend to have a relationship with life-style such as regular exercise and nonexercise Wassermann K et al. (1995). Pulmonary functions are generally determined by the strength of respiratory muscles, compliance of the thoracic cavity, airway resistance and elastic recoil of the lungs Cotes JE (1979) PFT provide qualitative and quantitative assessment of pulmonary function in patients with obstructive and restrictive lung diseases. Aerobic workout and other traditional physical activity like yoga and Tai Chi Chuan exercise can improve lung function in men and asthmatic children Chanavirut $\mathrm{R}$ et al (2006) \& Chang YF (2008). Duration of exercise, its type and intensity also have effects on lung functions Losnegard T \& Hallén J (2004), Galy O et al (2014).

The pulmonary function capacities of normal sedentary individuals have been studied extensively in India Aggarwal AN et al. (2000) but less in the context of comparison with different types of sports activities that are of a similar nature, according to the type and intensity of exercise performed, which could lead to the misclassification or misdiagnosis of certain respiratory dysfunctions. Furthermore, it is possible that highly trained athletes develop maladaptive changes in the respiratory system — such as intrathoracic and extrathoracic obstruction; expiratory flow limitation; respiratory muscle fatigue; and exercise-induced hypoxemia - that can influence their performance Losnegard T \& Hallén J (2014). Moreover, some studies have reported positive adaptive changes in lung function in comparison with sedentary individuals MacAuley D et al.(1999). Forced Vital Capacity (FVC) is the ability in which lungs exhale maximum amount of air present and is a strong 
indicator of lung function, which decline due to sedentary life style Jakes RW et al (2002). The purpose of this study was to examine and compare pulmonary function through Forced Vital Capacity (FVC) in different types of sports that are of a similar nature, according to the type and intensity of exercise performed i.e. Basketball, Volleyball, Boxing, Wrestling, Athletics, Swimming and compare them with controls in order to find out which sports improve lung function the most.

\section{Methodology}

The present study was conducted on 240 subjects of eight different games (30 of each): Basketball

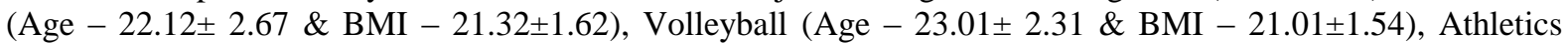
(Long Distance Runners) (Age - 23.62 2.17 \& BMI - 20.12 \pm 1.44 ), Athletics (Short Distance Runners) (Age $-21.32 \pm 2.06 \&$ BMI $-22.02 \pm 1.91$ ), Boxing (Fly to Middle weight boxers) (Age - 22.62 $\pm 2.06 \&$ BMI 21.32 \pm 1.51 ), Wrestling (57 to $86 \mathrm{~kg}$ ) (Age - 23.62 2.17 \& BMI - 20.12 \pm 1.44 ) Swimming (Age - 22.22 2.37

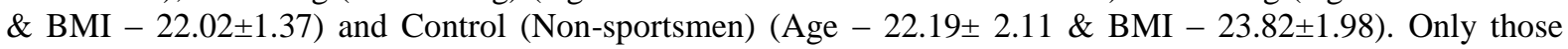
players are selected in the sports category that represented their Universities/State (Haryana, India) in the All India Interuniversity/National in their respective sports discipline in 2016 and were engaging in that sport for $\geq 16 \mathrm{~h}$ per week. In non sportsmen category only those students were selected, who were pursuing their master's degree from Kurukshetra University and had never participated in any competitive sports. The Force Vital Capacity (FVC) was measured with Minispir® New, Computer-based Spirometer, Medical International Research S.r.l. -via del Maggiolino 125, 00155 Roma, Italy - P.IVA IT04564101006, USA - MIR Medical International Research USA.

\section{Results}

Table - 1: Analysis various (ANOVA) For Force Vital Capacity (FVC) Liters/seconds in the subjects of various categories

\begin{tabular}{|c|c|c|c|c|c|}
\hline Sources of Variation & Sum of squares & df & Mean square variance & F. Value & $\mathbf{P}$ \\
\hline Between Groups & 65.970 & 7 & 9.42 & \multirow{2}{*}{$33.23 * *$} & \multirow{2}{*}{$<0.001$} \\
\hline With in Groups & 77.71 & 274 & 0.28 & & \\
\hline Total & 143.68 & 281 & & & \\
\hline
\end{tabular}

For the Force Vital Capacity (FVC) L/S in the Subjects of various categories the F value is 33.23, which is more than the table value at 0.01 levels of significance. As F value is significant, it indicates that there exists significant difference within and between the all eight categories of subjects for Force Vital Capacity (FVC) L/S.

Table - 2: Significance of difference between Mean of Non-Sports persons and players of various Sports Categories for Force Vital Capacity (FVC)

\begin{tabular}{|l|l|l|l|l|l|}
\hline $\begin{array}{l}\text { Sr. } \\
\text { No. }\end{array}$ & Categories & $\begin{array}{l}\text { Mean of First } \\
\text { Group }\end{array}$ & $\begin{array}{l}\text { Mean of } \\
\text { Second Group }\end{array}$ & S.E.D. & T-Value \\
\hline 1. & Non-Sports v/s Basket Ball & $3.96 \pm 0.39$ & $5.29 \pm 0.57$ & 0.14 & $13.47^{* *}$ \\
\hline 2. & Non-Sports v/s Athletic (SDR) & $3.96 \pm 0.39$ & $4.23 \pm 0.57$ & 0.15 & $2.04^{*}$ \\
\hline 3. & Non-Sports v/s Athletic (LDR) & $3.96 \pm 0.39$ & $4.29 \pm 0.57$ & 0.18 & $2.25^{*}$ \\
\hline 4. & Non-Sports v/s Swimming & $3.96 \pm 0.39$ & $4.68 \pm 0.55$ & 0.15 & $5.65^{* *}$ \\
\hline 5. & Non-Sports v/s Volley Ball & $3.96 \pm 0.39$ & $5.32 \pm 0.43$ & 0.14 & $12.91^{* *}$ \\
\hline 6. & Non-Sports v/s Boxing & $3.96 \pm 0.39$ & $4.64 \pm 0.57$ & 0.11 & $6.67^{* *}$ \\
\hline 7. & Non-Sports v/s Wrestling & $3.96 \pm 0.39$ & $4.66 \pm 0.40$ & 0.13 & $7.06^{* *}$ \\
\hline
\end{tabular}

According to above table the significant difference in the means of Force Vital Capacity (FVC) between the non-sportsmen and sportsmen of various categories, it is indicated that mean Force Vital Capacity (FVC) of non-sportsmen and basketball is 3.96 and 5.29 respectively and the t-value is $13.47(\mathrm{p}<0.001$, one tail test). Whereas, when FVC (L/S) of non-sportsmen (M - 3.96 \pm 0.39$)$ and Athletes (Short Distance Race) (M $4.23 \pm 0.57)$ were compared the $\mathrm{t}$-value is found to be $2.04(\mathrm{p}<0.021$, one tail test). Similarly, the mean Force Vital Capacity of non-sportsmen (M - 3.96 $\pm 0.39 \mathrm{~L} / \mathrm{S})$ and Athletes (Short Long Distance Race) $(\mathrm{M}-4.29 \pm 0.57$ $\mathrm{L} / \mathrm{S}$ ) with $\mathrm{t}$ - value 2.25 ( $\mathrm{p}<0.022$, one tail test).

The $\mathrm{t}$ - value of Force Vital Capacity (FVC) (L/S) for Non-Sports (M - 3.96 \pm 0.39$)$ v/s Swimming (M $4.68 \pm 0.55)$ was $5.65(\mathrm{p}<0.001)$ and that of Non-Sports $(\mathrm{M}-3.96 \pm 0.39)$ and Volley Ball $(5.32 \pm 0.43)$ was 12.91(p<0.001). Whereas, when the mean Force Vital Capacity (L/S) of Boxers $(\mathrm{M}-4.29 \pm 0.57 \mathrm{~L} / \mathrm{S})$ and Wrestlers $(\mathrm{M}-4.66 \pm 0.40)$ were compared with non sportsmen the $\mathrm{t}$ - value (one tail test) were $6.67(\mathrm{p}<0.002)$ and $7.06(\mathrm{p}<0.002)$ respectively. 


\section{Discussion Of Results}

According to results $\mathrm{t}$ - value for one tail test is found to be significant, when different categories were compared with the nonsportsmen i. e. Basketball - 13.47 ( $\mathrm{p}<0.001)$, Athletes (Short Distance Race) - 2.04 ( $\mathrm{p}<$ 0.021), Athletes (Long Distance Race) - 2.25 ( $\mathrm{p}<0.022)$, Swimming - 5.65(p<0.001), Volley Ball 12.91 $(\mathrm{p}<0.001)$, Boxers $-6.67(\mathrm{p}<0.002)$ and Wrestlers $-7.06(\mathrm{p}<0.002)$. The results discussed above indicate that players of basketball, Volleyball, athletes (both LDS and SDS), Boxers and Swimmers who have at least represented university and state (Haryana) had higher values of FVC compared to the controls. It contrasts with previous reports which found that all athletes, regardless of the sport, had higher lung volumes than physically inactive persons Armour J et al.(1993), Mehrotra PK et al. (1998), Jakes RW et al.(2002), Janssen I (2009), Sable M et al.(2012), Shin YS et al. (2016).Mazic S et al. (2006) found that in Serbian elite Basketball, water polo players and rowers had statistically higher vital capacity (VC), forced vital capacity (FVC), forced expiratory volume in one second (FEV1) than the healthy sedentary control individuals. Shin YS et al. (2016) reported that the respiratory function of Korean wrestling athletes is better than that of non-athletes as analysis of the FVC graph revealed that the Korean wrestlers, athletes and the non-athletes were significantly different. The respiratory muscles of the athletes were anticipated to be better than those of the non-athletes.

In a cross-sectional study conducted by Myrianthefs et al. (2014), which included 276 athletes engaged in various sports, the results were similar to those obtained in our study. One possible explanation is that every sport differs in terms of the type and intensity of the exercise involved, which varies by season, as well as that there are sport-specific adaptations of body composition, a phenomenon known as "sport-specific morphological optimization" Berglund L. et al. (2011). Sabe M et al. (2012) swimming exercise affects lung volume measurements as respiratory muscles including diaphragm of swimmers are required to develop greater pressure as a consequence of immersion in water during respiratory cycle, thus may lead to functional improvement in these muscles and also alterations in elasticity of lung and chest wall or of ventilatory muscles, leading to an improvement in forced vital capacity and other lung functions of swimmers than runners. It is recognized that the respiratory muscles will adapt to aerobic training Losnegard T et al (2014). Most aerobic athletes have very well trained respiratory muscles from their sport alone. However, it is not known if additional respiratory muscle training could elicit positive adaptations within the aerobically trained athlete that would make the ventilatory process more efficient. During competition athletes will take thousands of breaths. Like all other skeletal muscles, the pulmonary muscles when engaging in aerobic metabolism require oxygen. The fatigue resistance of this process is related to the training status of the muscle. If the muscle is more endurance trained, then it will be less likely to constrain ventilation and exercise performance.

Akabas et al. (1989) an increase in aerobic enzymes during exercise in humans would equate to more efficient energy utilization of the respiratory muscles and lower fatigueability. Boutellier U et al. (1992) suggest resistance training offers some benefit to fatigue resistance in untrained students. The research also suggests that inspiratory muscles, like all other skeletal muscles, adapt according to the stress placed on them. William E et al.(2002) because the subjects had trained their pulmonary muscles, they were able to increase ventilation. The increase in Ventilation in $\mathrm{L} / \mathrm{min}$ and decrease in Respiratory rate in the training group indicated that the Powerlung device increased the strength of the respiratory muscles. The increased strength of the respiratory muscles allowed the subjects to perform more work (i.e. move more air) while breathing fewer times.

As the lung volumes depend on height, higher values are expected in all tall athletes Laszlo (2006). We found higher value of FVC in basketball and Volleyball players, who were significantly taller than other sportsmen and controls. There was no difference in height among Wrestlers, Boxers, Athletes and swimmers, it would suggest that although height and age are the most commonly used predictive factors for lung volumes, other factors, thoracic diameter and trunk length, may predict lung volume in athletes. It is therefore likely that both anatomical and mechanical factors may account for differences in lung volume Cotes JE et al. (2001) \& Lazovic B et al. (2015).Our results suggest that the type of sport has a significant impact on respiratory adaptation. Because of these sport-specific differences, there is a need for further investigations examining sports specific and exercise specific; the influence of the duration, severity, and intensity of exercise; the early years of training; respiratory muscle strength; and specific genetic influences.

\section{Conclusion}

This study agrees with previous reports and supports that regular exercise improves lungs functions. The study revealed that the sedentary subject's performance on FVC was poorer when compared with sportsmen who have been engaged in sports for $\geq 16 \mathrm{~h}$ per week and represented their Universities/State (Haryana, India) in the All India Interuniversity/National in Basketball, Volleyball, Boxing, Wrestling, Athletics and Swimming. Volleyball and Basketball players were having highest value of FVC. However, although the unique anthropometric characteristics of successful players of Volleyball and basketball have, as previously mentioned, been shown to be mostly attributable to genetic endowment, it remains unclear whether the superior lung function found in such athletes is due to genetic influences or to the specific pattern of exercise. 


\section{References}

[1]. Aggarwal AN, Gupta D, Chaganti S, Jindal SK. Diurnal variation in peak expiratory flow in healthy young adults. Indian J Chest Dis Allied Sci. 2000;42:15-9.

[2]. Akkbas SR, Bazzy AR, Dimauro S, \& Haddad GG. Metabolic and Functional adaptation of the diaphragm to training and resistive loads. J Appl Physiol 1989;66(2):529-535.

[3]. Armour J, Donnelly PM, Bye PT. The large lungs of elite swimmers: an increased alveolar number? Eur Respir J.1993;6(2):237-47.

[4]. Berglund L, Sundgot-Borgen J, Berglund B. Adipositas athletica: a group of neglected conditions associated with medical risks. Scand J Med Sci Sports, 2011;21(5):617-24. http://dx.doi.org/10.1111/j.1600- 0838.2011.01322.x

[5]. Boutellier U, Baechel R, Kudent A, \& Piwko, R. The respiratory system as an exercise limiting factor in normal trained subjects. Eur J Appl Physiol 1992;65:347-353.

[6]. Chanavirut R, Khaidjapho K, Jaree P, and Pongnaratorn P. Yoga exercise increases chest wall expansion and lung volumes in young healthy Thais. THAI J PHYSIO SCINCES. Volume 19 (No.1, April 2006;19(1):1-7

[7]. Chang YF, Yang YH, Chen CC, Chiang BL. Tai Chi Chuantraining improves thpulmonary function of asthmaticchildren. J Microbiol Immunol Infect 2008; 41 (1): 88- 95.

[8]. Cotes JE. Lung Function: Assessment and Applications in Medicine. 4th ed. Oxford: Blackwell Scientific Publications; 1979.

[9]. Cotes JE, Chinn DJ, Reed JW. Body mass, fat percentage, and fat-free mass as reference variables for lung function: effects on terms for age and sex. Thorax. 2001;56:839-44.

[10]. Galy O, Ben Zoubir S, Hambli M, Chaouachi A, Hue O, Chamari K. Relationships between heart rate and physiological parameters of performance in top-level water polo players. Biol Sport. 2014;31(1):33- 8 .

[11]. http://dx.doi.org/10.5604/20831862.1083277

[12]. Jakes RW, Day NE, Patel B, Khaw KT, Oakes S, Luben R, et al. Physical inactivity is associated with lower forced expiratory volume in 1 second : European Prospective Investigation into Cancer-Norfolk Prospective Population Study. Am J Epidemiol. 2002;156(2):139-47

[13]. Laszlo. Standardisation of lung function testing: helpful guidance from the ATS/ERS task force. Thorax. 2006;61(9):744-6.

[14]. Lazovic B, Mazic S, Suzic-Lazic J, Djelic M, Djordjevic-Saranovic S, Durmic T, et al. Respiratory adaptations in different types of sport. Eur Rev Med Pharmacol Sci. 2015;19(12):2269-74

[15]. Losnegard T, Hallén J. Elite cross-country skiers do not reach their running VO2max during roller ski skating. J Sports Med Phys Fitness. 2014;54(4):389-93.

[16]. Losnegard T, Hallén J. Elite cross-country skiers do not reach their running VO2max during roller ski skating. J Sports Med Phys Fitness. 2014;54(4):389-93.

[17]. MacAuley D, McCrum E, Evans A, Stott G, Boreham C, Trinick T. Physical activity, physical fitness and respiratory function-exercise and respiratory function. Ir J Med Sci. 1999;168(2):119-23. http:// dx.doi.org/10.1007/BF02946480

[18]. Mazic S, Lazovic B, Djelic M, Suzic-Lazic J, Djordjevic-Saranovic S, Durmic T, Soldatovic I, Zikic D, Gluvic Z, Zugic V. Respiratory parameters in elite athletes--does sport have an influence? Rev Port Pneumol (2006). 2015 Jul-Aug;21(4):192-7. doi: 10.1016/j.rppnen.2014.12.003. Epub 2015 Feb 16.

[19]. Mehrotra PK, Varma N, Tiwari S, Kumar P. Pulmonary functions in Indian sportsmen playing different sports. Indian J Physiol Pharmacal. 1998;42(3):412-6.

[20]. Physical Activity Guidelines Advisory Committee (PAGAC). Physical Activity Guidelines Advisory Committee Report, 2008. Washington, DC, US Department of Health and Human Services, 2008.

[21]. Sable M, Vaidya SM, Sable SS. Comparative study of lung functions in swimmers and runners. Indian J Physiol Pharmacol. 2012 Jan-Mar;56(1):100-4.

[22]. Shin YS, Yang SM, Kim MY, Lee LK, Park BS, Lee WD, Noh JW, Kim JH, Lee JU, Kwak TY, Lee TH, Kim JY, Park J, Kim J. Analysis of the respirogram phase of Korean wrestling athletes compared with nonathletes for sports physiotherapy research. J Phys Ther Sci. 2016 Jan;28(2):392-8. doi: 10.1589/jpts.28.392. Epub 2016 Feb 29

[23]. Wassermann K, Gitt A, Weyde J, Eckel HE. Lung function changes and exercise-induced ventilatory responses to external resistive loads in normal subjects. Respiration. 1995;62:177-84.

[24]. William E.,Amonette, Terry L D., The effects of respiratory muscle training on Vo2 max., the ventilatory threshold and pulmonary function. Journal of Exercise Physiology. 2002;5 (2): 29-35.

[25]. WHO, World Health Statistics (2016),

[26]. www.who.int/gho/publications/world_health_statistics/2016/en/

[27]. WHO, Global recommendations on physical activity for health (2010).

[28]. http://apps.who.int/iris/bitstream/10665/44399/1/9789241599979_eng.pdf 